\title{
The Effects of Knowledge Management on the Process of Employee Innovation within Organizations
}

\author{
Dr. Pu Xu ${ }^{1}$ and Dr. Jingjing Wang ${ }^{2}$ \\ ${ }^{1}$ Shanghai Ocean University, Shanghai, China \\ ${ }^{2}$ University of Tasmania, Hobart, 7000, Australia \\ Jingjing.Wang@utas.edu.au
}

\begin{abstract}
The need for organizations to innovate is highlighted throughout the management literature on innovation. Knowledge is considered as a potential key competitive advantage by helping to facilitate innovation within the organization. This paper focuses on the role of knowledge management in enhancing employee innovation in organizations. In particular, this paper attempts to review the innovation and knowledge management literature in a systematic way. From the literature review, this paper paves the way for future studies to further examine and develop the possible model which incorporates employee innovation and knowledge management. Further research is needed to consider investigating the effects of knowledge management on employee innovation.
\end{abstract}

Index Terms - employee innovation, knowledge management, innovation process

\section{Innovation and Its Importance}

Innovation is the introduction of new and improved ways of doing things at work. According to McAdam \& Keogh[1], innovation is essential for organizational competitiveness and success. Yuan and Woodman[2] also claimed that innovation has been widely recognized as an important source of competitive advantage for organizations that want to prosper and grow. Therefore, it is not surprising that a significant amount of literature has been generated on the subject of innovation, which has become a broad concept that can be defined in many ways.

The literature on innovation is diverse and complex, and it covers many subject and research fields such as organizational behaviour, education and sociology. Meanwhile, Damanpour [3], Damanpour, Szabat and Evan[4] suggested, the theories discussed hold true in different circumstances relating to the types and stages of innovation.

To clarify the interpretation and usage of the construct of innovation, it is necessary to define the term "innovation" and what it is concerned with here. As King and Anderson[5] and West and Farr[6] suggested, the common features that underlie innovation include the concepts of novelty, potential usefulness to the organization, and implementation. According to the extant work including Pitt[7], Davenport, Jarvenpaa and Beers[8], Demerest[9], there are three broad categories of innovation identified in the literature:

- Strategic innovative management to assist the organization in the challenges faced by its environment;

- Management of innovative change initiatives;

- Innovation through knowledge creation and application.
Following Tushman, Anderson and O'Reilly[10], within each category, innovation can be ranked from incremental to breakthrough. While the first two categories have been widely addressed, few studies have examined innovation through knowledge creation and application. Therefore, given the importance of knowledge to innovation, this paper exclusively focuses on this area here: how innovation related to knowledge.

\section{Employee Innovation within Organization}

Innovative behavior by employees is at the root of every innovation. The previous studies including $\mathrm{Lu}$ and $\mathrm{Li}$ [11]suggested that employee innovation is important for organizations. To meet the needs of global competition and the uncertain environment, as Axtell ET al. [12] suggested, organizations need their employees to undertake not only basic duties, but also make extra efforts to act beyond the routine performance of their duties in order to engage in innovative behavior in work processes. This illustrates that the innovative behavior of employees deserves research attention.

The literature revealed the importance of organization's influences on employee innovation. Scott and Bruce[13], Hunter, Bedell and Mumford[14]highlighted that the generation of new ideas and the translation of these ideas into useful practices are functions of interactions between employees and situations. According to Anderson[15], a supportive work context plays an important role in supporting and encouraging employees' innovative efforts. It also suggests that management should consider their organizations' effects on employees if they are interested in maximizing their employees' innovative behavior in the workplace.

Specifically, Shalley and Gilson[16] suggested that for innovation to occur in organizations, management needs to support and promote it, as they have considerable influence over the context within which idea generation can occur. In this way, as Amabile[17] stated, the context in which an employee performs a task influences his or her intrinsic motivation, which in turn affects innovative achievement. Seibert, Kraimer and Crant [18] suggested that employees are most likely to engage in activities that promote their ideas when both a supportive work context is present and they have a proactive personality.

The present study addresses the research need by extending research on the influence of organization on employee innovation - in particular, understanding employee innovation from knowledge management's perspective. This 
study is expected to advance the understanding of the process of employee innovation within organization from the perspective of knowledge management and pave the way for future studies in this field.

\section{The Process of Innovation from Knowledge Perspective}

Innovation could be viewed as a complex process that involves a set of investment possibilities. In this investment perspective, as Carneiro [19] suggested, knowledge must be considered a sort of capital. Prior work such as Harari[20], Nonaka [21], suggested that organizations that are able to stimulate and improve the knowledge of their human capital are more prepared to face today's rapid changes and to innovate in the domain where they decide to invest and compete. This indicates the importance of knowledge management for organizations to encourage their employees to innovate in the workplace.

Following Demerest[9], knowledge management includes new knowledge construction, knowledge embodiment, knowledge dissemination and knowledge use/benefit. This implies that knowledge management has the potential to be a catalyst for innovation within organization. In this way, as McAdam and McCreedy[22] found, effective systematic knowledge management can incorporate innovation drivers in key areas which will lead to increased business and employee benefits.

Within organizations, the emergence of innovation in the workplace depends on both employee innovation and team innovation. However, few studies have focused on the interaction between these two levels. From a process perspective and a knowledge perspective, this paper considers the process of innovation as an interactive process of transformation between the individual and team knowledge.

\section{A. Classification of knowledge}

For the purpose of this paper, the researchers suggest that there are three broad categories of knowledge identified in the literature: fragmented knowledge, internalised knowledge, and explicit knowledge.

Fragmented knowledge refers to the implicit knowledge gaining from outside based on learning and memory without any processing, as well as something found in the workplace including the observations of exceptive phenomenon or inspiration. Internalised knowledge is about new implicit knowledge generated by the innovator from the in-depth thinking and integration of the fragmented knowledge, as well as the long-term working experiences. When such internalised knowledge is recorded by tangible carriers such as document, audio, video, it is transformed to explicit knowledge which can be diffused between different parties. It is worth noting that the essence of fragmented knowledge and internalised knowledge is one of implicit knowledge.

The emergence of innovation through knowledge creation and application usually happens within the team. According to Jackson[23], teams become the common work unit for managing changes. The researchers classified the knowledge for innovation into six groups (see Table 1). Essentially, the process of employee innovation can be understood as the interactive process of innovation through the transformations between these six categories of knowledge. This knowledge transformation process will be elaborated in the following section.

TABLE I Classification of Knowledge

\begin{tabular}{|c|c|c|c|}
\hline & $\begin{array}{c}\text { Explicit } \\
\text { knowledge }\end{array}$ & $\begin{array}{c}\text { Fragmented } \\
\text { knowledge }\end{array}$ & $\begin{array}{c}\text { Internalized } \\
\text { knowledge }\end{array}$ \\
\hline $\begin{array}{c}\text { Employee } \\
\text { level }\end{array}$ & $\begin{array}{c}\text { employee's } \\
\text { explicit } \\
\text { knowledge }\end{array}$ & $\begin{array}{c}\text { Employee's } \\
\text { fragmented } \\
\text { knowledge }\end{array}$ & $\begin{array}{c}\text { Employee's } \\
\text { internalized } \\
\text { knowledge }\end{array}$ \\
\hline $\begin{array}{c}\text { Team } \\
\text { level }\end{array}$ & $\begin{array}{c}\text { Team's explicit } \\
\text { knowledge }\end{array}$ & $\begin{array}{c}\text { Team's fragmented } \\
\text { knowledge }\end{array}$ & $\begin{array}{c}\text { Team's internalized } \\
\text { knowledge }\end{array}$ \\
\hline
\end{tabular}

B. The process of employee innovation from knowledge management perspective

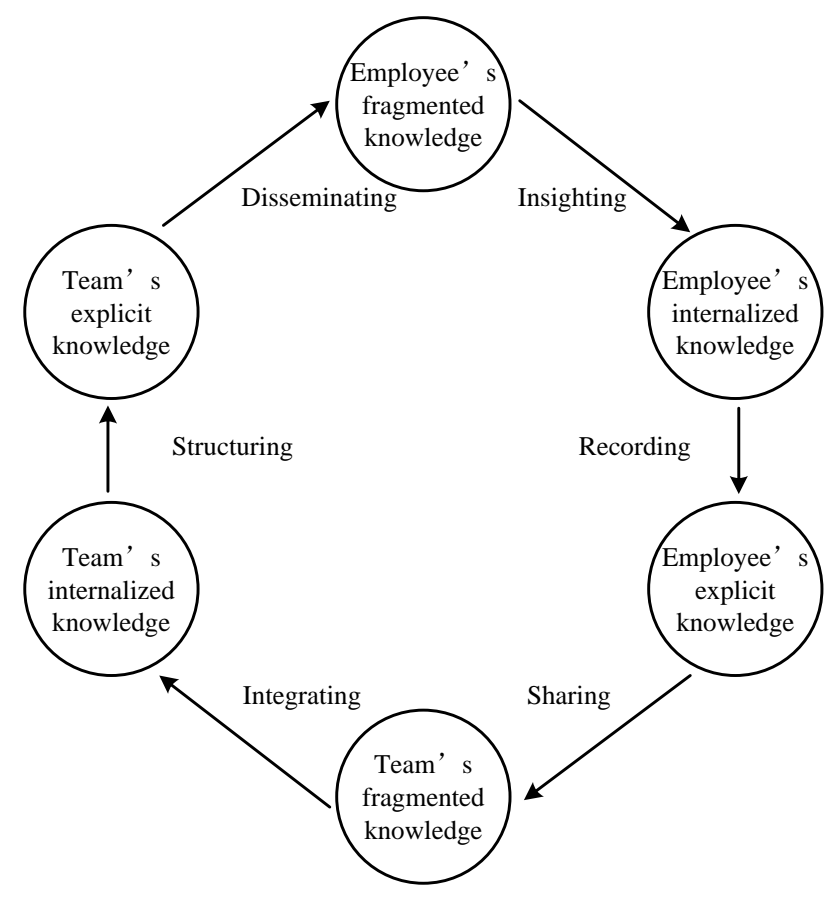

Fig. 1 The process of employee innovation

\section{1) Employee's fragmented knowledge-employee's internalized knowledge}

There are different sources of employee's fragmented knowledge. It can be sourced from information collected from Internet search engine and database, newspaper or magazines, or valuable information collected from formal or informal communications. After an intuitive grasp and a preliminary selection, those information and knowledge will become employee's fragmented knowledge which is only a temporary. When the employee receives an assignment, the assignment will be broken into several sub problems. At the same time, the employee will search for the potential useful fragmented knowledge gained before. 
During employee fragmented knowledge-internalized knowledge transformation process, the employee will search for fragmented knowledge which can be used to solve the problem from the knowledge base in the head, and also absorb new information and stimulate inspirations from daily work. By integrating above elements, the employee will arrive at a solution-employee's internalized knowledge via in-depth understanding and thinking.

\section{2) Employee's internalized knowledge - Employee's explicit knowledge}

Since the internalized knowledge generated via in-depth understanding and systematic thinking cannot remain forever on an employee's memory, it will be recorded in different forms such as audios, videos, tables, figures, documents.

It means employee's explicit knowledge needs tangible mediums as carriers. When employees talk and share their thoughts together, such knowledge generated from oral conversations cannot be seen as the transformation from employee's internalized knowledge towards employee's explicit knowledge unless they are recorded via tangible mediums.

\section{3) Employee's explicit knowledge - Team's fragmented knowledge}

As the extant work including Nonaka and Takeuchi [24] suggested, employee's explicit knowledge is turning into team's fragmented knowledge when employees pass their explicit knowledge onto others. Such sharing knowledge process usually takes the forms of group discussion, meetings or brain storms activities. During this process, explicit knowledge from different employees will be shared together without any group thinking. Those information and knowledge will be turned into fragmented knowledge at team level which is only a temporary.

\section{4) Team's fragmented knowledge - team internalized knowledge}

Based on sharing knowledge and information with each other within team, employees will integrate the fragmented knowledge together to reach a solution. Such a process as telling stories about experiences is shared by all the employees within that team together, and it is about an interactive process of transformation between fragmented knowledge and internalized knowledge within team. It is worth noting that some knowledge will be stored in the team's knowledge base for future use.

\section{5) Team's internalized knowledge - team's explicit knowledge}

Based on the group discussions, employees will reach an agreement about the solution and the relevant details. Such solution and agreements are teams' internalized knowledge, which is an outcome of team innovation. The diffusion of such innovation can improve team efficiency.

It is noted that team's explicit knowledge also needs tangible mediums as carriers. It is believed that diffusing and sharing team's explicit knowledge can facilitate the leaning and communication between employees.

\section{6) Team's explicit knowledge - Employee's fragmented knowledge}

Some team's explicit knowledge will be turned into standard procedures and rules for learning and promotion following a top - down style within organization in order to improve efficiency. Other knowledge will be stored in knowledge base for future use. Based on such learning and absorbing process of employees, explicit knowledge at team level will be turned into employee's fragmented knowledge for problem solutions.

Overall, previous studies such as Wetlaufer [25] pointed out that the knowledge transformation process for innovation which involves small - group discussions between employees within organization requires an open and conductive environment. This implies the importance of a supporting environment for encouraging knowledge sharing and employee innovative behaviour in the workplace.

\section{Conclusions and Recommondations}

The relevant literature suggested that innovation can be closely related to knowledge, and effective systematic knowledge management can enhance employee innovation in the workplace. Based on the literature review, this paper emphasized that the essence of innovation process can be viewed as a knowledge transformation process among employees within organization. Investigating the innovation process from the perspective of different knowledge transformation could be one possible direction for future studies.

From a practical perspective, there are some recommendations for business who are interested in facilitating employee innovation within organizations.

First, business managers could provide organizational support such as maintaining good management of the organization's database, and providing training opportunities for their employees. By doing so, it might help to maximise employee innovative behaviour by providing them various sources of fragmented knowledge.

Second, investing in tangible reward and intangible recognition might encourage employees' knowledge sharing activities and their enthusiasm in the workplace.

Third, given the importance of the environment's effects on employee innovation, this paper recommends developing a good environment which encourages employees to share and communicate. A good environment might help to maximize employees' potential to innovate and to foster the diffusion of new ideas at work. Additionally, managing knowledge base in an efficient way, and tracking employees' learning process might also help to turn employee's knowledge into team/organization's knowledge.

Future research could consider synthetic interactions of different-level factors, including employee, team and organization levels on employee innovation, rather than investigate their influences separately. In particular, it is 
recommended that future research examine the combined effects of such personal and contextual conditions on employee innovation through knowledge creation and application in the workplace.

\section{Acknowledgment}

This research was supported by the research support scheme of University of Tasmania, Shanghai Association of Productivity Science, and Doctoral Fund of Shanghai Ocean University.

\section{References}

[1] R. McAdam and W. Keogh, "Transitioning Towards Creativity and Innovation Measurement in SMEs", Creativity and Innovation Management, vol. 13, no. 2, pp.126-139, 2004.

[2] F. Yuan and R.W. Woodman, "Innovative Behaviour in the Workplace: The role of Performance and Image Outcome Expectations", Academy of Management, vol. 53, no. 2, pp 323-342, 2010.

[3] F. Damanpour, "The Adoption of Technological, Administrative, and Ancillary Innovations: Impact of Organizational Factors", Journal of Management, vol. 13, pp. 675-688, 1987.

[4] F. Damanpour, K.A. Szabat and W.M. Evan, "The relationship between types of innovation and organizational performance", Journal of Management Studies, vol. 26, no. 6, pp. 587-602, 1989.

[5] N. King, NR. Anderson and MA. West, "Organizational innovation: A case study of perceptions and processes", Work and Stress, vol. 5, pp. 331-339, 1992.

[6] MA. West and JL. Farr, "Innovation at work: psychological perspectives", Social Behaviour, vol. 4, pp.15-30, 1989.

[7] M. Pitt, "The Knowledge Creating Company: How Japanese companies create the dynamics of innovation (book review)", Human Relations, vol. 51, no. 4, pp. 547-563, 1998.

[8] T. Davenport, S. Jarvenpaa S, and M. Beers, "Improving knowledge work processes", Sloan Management Review, vol. 37, no. 4, pp. 53-66, 1996.

[9] M. Demerest, "Understanding knowledge management", Journal of Long Range Planning, vol. 30, no.3, pp. 374-384, 1997.

[10] M.L. Tushman ML, C.A. Anderson, and C. O'Reilly, "Technology cycles, innovation streams, and ambidextrous organisations: organisational renewal through innovation streams and strategic change. In Managing Strategic Innovation and Change, Tushman ML, Anderson P (Eds). Oxford University Press: Oxford, 1997.
[11] X.J. Lu and P. Li, "The Impact of Learning Culture on Individual Innovative Behavior", in Management and Service Science (MASS), 2010 International Conference on, IEEE, pp. 1-4, 2010.

[12] C.M. Axtell, D.J. Holman, K.L. Unsworth, T.D. Wall, P.E. Waterson, and E. Harrington, "Shopfloor innovation: Facilitating the suggestion and implementation of ideas", Journal of occupational and organizational psychology, vol.73, no. 3, pp. 265-285, 2000.

[13] S.G. Scott and R.A. Bruce, "Determinants of innovative behavior: A path model of individual innovation in the workplace", Academy of management journal, vol. 37, no. 3, pp. 580-607, 1994.

[14] S.T.Hunter, K.E. Bedell and M.D. Mumford, "Climate for creativity: A quantitative review", Creativity Research Journal, vol. 19, no.1, pp. 6990, 2007.

[15] S.B. Anderson, "Encyclopedia of Educational Evaluation: Concepts and Techniques for Evaluating Education and Training Programs, 1975.

[16] L.L. Gilson and C.E. Shalley, "A Little Creativity Goes a Long Way: An Examination of Teamsâ€TM Engagement in Creative Processes", Journal of Management, vol. 30, no. 4, pp. 453-470, 2004.

[17] T.M. Amabile, A model of creativity and innovation in organizations. In B. M. Staw \& L. L. Cummings (Eds.), Research in organizational behavior, vol. 10, pp. 123-167. Greenwich, CT: JAI Press, 1988.

[18] S.E. Seibert, M.L. Kraimer and JM. Crant, "What do proactive people do? A longitudinal model linking proactive personality and career success", Personnel Psychology, vol. 54, no. 4, pp. 845-874, 2006.

[19] A. Carneiro, "How does knowledge management influence innovation and competitiveness", Journal of knowledge management, vol. 4, no. 2, pp. 87-98, 2000.

[20] O. Harari, "When intelligence rules, the manager's job changes", Management Review, vol. 83, no. 7, pp. 33-35, 1994.

[21] I. Nonaka, "A dynamic theory of organizational knowledge creation", Organization Science, vol. 5, no. 1, pp. 14-37, 1994.

[22] R. McAdamand and S. McCreedy, "The process of knowledge management within organizations", Journal of Knowledge and Process Management, accepted for publication, summer 1999.

[23] S.E. Jackson, "The consequence of diversity in multidisciplinary work teams", In M.A. West (Ed.), Handbook of work group psychology, pp. 53-75, London: Wiley, 1996.

[24] I. Nonaka and K.Takeuchi, "The Knowledge Creating Company: How Japanese companies create the dynamics of innovation", Oxford University Press: Oxford, 1995.

[25] S. Wetlaufer, "Driving change: an interview with Ford Motor Company's Jacuques Nassir", Harvard Business Review, vol. 77, no. 2, pp.76-88, 1999. 